\title{
Emergency medicine physician burnout and wellness in Canada before COVID19: A national survey
}

\author{
Rodrick Lim, MD*; Kristine Van Aarsen (1), Msc; Sara Gray, MD; Louise Rang, MD\|; \\ Jada Fitzpatrick, $\mathrm{MD}^{* *}$; Lisa Fischer, $\mathrm{MD}^{\dagger \dagger}$
}

\section{CLINICIAN'S CAPSULE}

What is known about the topic?

Emergency department (ED) physicians have been previously identified outside of Canada as a high-risk specialty for burnout.

What did this study ask?

What is the burnout rate among ED physicians in Canada just before COVID-19?

What did this study find?

Canadian physicians experience high rates of burn-out, with $86.1 \%$ meeting at least one of the criteria for burnout in Canada just before COVID-19.

Why does this study matter to clinicians?

Front-line staff will be adversely affected by COVID-19 both during and after the pandemic. Baseline data are needed.

\section{ABSTRACT}

Introduction: Emergency medicine (EM) is a high-risk specialty for burnout. COVID-19 has had and will continue to have important consequences on wellness and burnout for EM physicians in Canada. Baseline data are crucial to monitor the health of EM physicians in Canada, and evaluate any interventions designed to help during and after COVID-19.

Objectives: To describe the rates of burnout, depression, and suicidality in practicing EM physicians in Canada, just before the COVID-19 pandemic.

Methods: A modified snowball method was used for survey distribution. Participants completed the Maslach Burnout Inventory-Health Services Tool (MBI-HSS), a screening measure for depression (PHQ-9), and a question regarding if the physician had ever or in the past 12 months contemplated suicide.
Results: A total of 384 respondent surveys were included in the final analysis: $86.1 \%(329 / 382)$ met at least one of the criteria for burnout, $58 \%$ (217/374) scored minimal to none on the PHQ-9 screening tool for depression, $14.3 \%$ (53/371) had contemplated suicide during their staff career in EM, and of those, $5.9 \%$ (22/371) had actively considered suicide in the past year.

Conclusion: Canadian EM physicians just before the COVID-19 pandemic had an alarming number of respondents meet the threshold for burnout, confirming EM as a high-risk specialty. This important baseline information can be used to monitor the physical and mental risks to EM physicians during and after COVID-19, and evaluate support for mental health and wellness, which is urgently needed now and post pandemic.

\section{RÉSUMÉ}

Introduction: La médecine d'urgence (MU) est une spécialité qui comporte un risque élevé d'épuisement professionnel. La pandémie de COVID-19 a eu et continuera d'avoir des répercussions importantes sur le mieux-être et l'épuisement professionnel des médecins d'urgence au Canada. Des données de base revêtent donc une importance cruciale dans la surveillance de l'état de santé des urgentologues au Canada ainsi que dans l'évaluation des interventions conçues pour améliorer leur mieux-être durant et après la pandémie.

Objectif: L'étude visait à déterminer les taux d'épuisement professionnel, de dépression et d'idéation suicidaire chez les praticiens de la médecine d'urgence au Canada, juste avant I'arrivée de pandémie de COVID-19.

Méthode: L'enquête a été menée selon une version modifiée de la méthode d'échantillonnage en boule de neige, ou par relations. Les participants devaient remplir le questionnaire Maslach Burnout Inventory - Health Services Tool (MBIHSS), un instrument de dépistage de la dépression (PHQ-9),

From the *Division of Pediatric Emergency Medicine, Departments of Pediatrics \& Medicine, Schulich School of Medicine and Dentistry, London, ON; ${ }^{\dagger}$ Children's Health Research Institute, London Health Sciences Centre, London, ON; ${ }^{\ddagger}$ Division of Emergency Medicine, Department of Medicine, Schulich School of Medicine and Dentistry, London, ON; ${ }^{\S}$ Department of Emergency Medicine, University of Toronto, Toronto, ON; "Department of Emergency Medicine, Queen's University, Kingston, ON; ${ }^{* *}$ Department of Emergency Medicine, McMaster University, Hamilton, ON; and ${ }^{\dagger \dagger}$ Departments of Emergency Medicine and Medicine, Division of Palliative Care, University of Ottawa, Ottawa, ON.

Correspondence to: Dr. Rodrick Lim, London Health Sciences Centre, 800 Commissioners Road East, London, Ontario, N6A 2V5; Email: rod.lim @ Ihsc.on.ca

(c) Canadian Association of Emergency Physicians 2020

CJEM 2020;22(5):603-607

DOI 10.1017/cem.2020.431 
en plus de répondre à une question sur la présence d'idéations suicidaires au cours des 12 derniers mois, ou encore à un moment ou à un autre de leur carrière.

Résultats: Au total, 384 répondants ont été retenus dans l'analyse finale. Ainsi, 86,1\% (329/382) d'entre eux répondaient à au moins à l'un des critères d'épuisement professionnel; $58 \%$ $(217 / 374)$ ont obtenu un résultat entre 0 et le score minimal de dépression sur l'échelle PHQ-9; 14,3\% (53/371) ont eu des idéations suicidaires au cours de leur carrière en $\mathrm{MU}$, dont $5,9 \%(22 / 371)$ ont sérieusement envisagé le suicide au cours de la dernière année.
Conclusion: Un nombre alarmant de médecins d'urgence au Canada satisfaisaient au seuil d'épuisement professionnel juste avant l'arrivée de la pandémie de COVID-19, ce qui confirme le caractère à haut risque de la MU. Il s'agit là de données de base importantes, car elles peuvent servir à la surveillance des risques pour la santé mentale et physique des urgentologues durant et après la pandémie de COVID-19, ainsi qu'à l'évaluation des mesures de soutien visant à améliorer leur mieux-être et leur état mental, mesures dont ils ont et auront grandement besoin maintenant et plus tard.

Keywords: Emergency medicine, physician wellness, COVID-19

\section{INTRODUCTION}

International data indicates that emergency medicine (EM) is one of the most unwell professions with a high risk for burnout. ${ }^{1-4}$ (Additional references available in the online Supplemental Appendix.) Consequences of burnout in medicine are severe and impact patient care, the health care system, and physician health. ${ }^{5}$ Burnout results in lower quality care, increased medical errors, lower patient satisfaction, increased physician turnover, increased cost, and lower productivity. ${ }^{5}$ Physician health effects include increased substance abuse, depression, and suicidal ideation. ${ }^{5}$ COVID-19 has fundamentally disrupted the world and EM physicians are at extensive risk of further health-related and psychological injury. ${ }^{6}$ Studies have indicated a risk of depression, anxiety, and mental health complaints in the frontlines in China during the early days of COVID-19. ${ }^{7}$ A baseline on the current rate of burnout, depression, and suicidality of EM physicians in Canada would be of great importance to monitor their health during and post-COVID pandemic and the effect of any wellness interventions to support them.

\section{METHODS}

\section{Survey design}

The survey tool available in English included demographic information, the Maslach Burnout Inventory Health Services Tool (MBI-HSS), Patient Health Questionnaire (PHQ-9), and a question regarding if the physician had ever or in the past 12 months contemplated suicide. The survey was pilot tested and reviewed for accuracy among ED doctors from lead authors home institution.

The MBI-HSS is a standardized validated 22-item tool that scores questions on a 7-point Likert scale, across three dimensions: emotional exhaustion, depersonalization, and personal achievement. ${ }^{8}$ The PHQ-9 is a standardized validated instrument for screening and measuring the severity of depression in five categories. This study was approved by Western University's Health Science Research Ethics Board.

\section{Survey distribution}

The survey was distributed using a modified snowball method. An invitation to join a roster (February to May 2019) was sent by means of the Canadian Association of Emergency Physicians (CAEP) survey distribution network, posted on social media (Facebook, Twitter, CAEP website), and physical posters at the 2019 CAEP Annual Conference. Rostered physicians were then asked to forward the invitation to any EM physician in Canada. The survey was distributed in June 2019 with reminders sent at week 2 and 4 post invitation. The total sample size was not captured. All data were collected anonymously using the REDCap platform housed at the host institution, and responses were reported in aggregates.

\section{Outcome measures}

The primary outcome was the percentage of EM physicians who met the criteria for burnout. The MBI-HSS was used to assess burnout on three dimensions (defined as emotional exhaustion $\geq 27$, depersonalization $\geq 10$, or 
personal accomplishment <34). ${ }^{9}$ Secondary outcomes were burnout rates by gender and years of practice. Percentage of respondents by severity of depression on the PHQ-9 scale, as well as percentage positive to suicidal ideation in career/past year, were obtained. A violin plot was created displaying the distribution of total score for each MBI domain to visualize the proportion above the MBI threshold.

\section{Data analysis}

Data were analyzed using SPSS version 23 (IBM Corp, Seattle, WA). Demographic information was analyzed descriptively. Categorical data were presented using proportions with percentages, and continuous data were tested for normality and presented as a median with interquartile range. Differences between groups were calculated using chi-square analyses.

As a secondary outcome, a logistic regression analysis was performed to assess which variables were associated with burnout. Variables were first analyzed in a univariate manner, and variables found to be associated $(p<0.1)$ with burnout were included as initial input in a multivariable model to determine which factors were independently associated with physician burnout.

Backward, stepwise multivariable logistic regression (Wald removal criterion 0.1) was used to determine predictor variables independently associated with burnout. Likelihood ratio tests were used to determine appropriate inclusion of variables in the multivariable model.

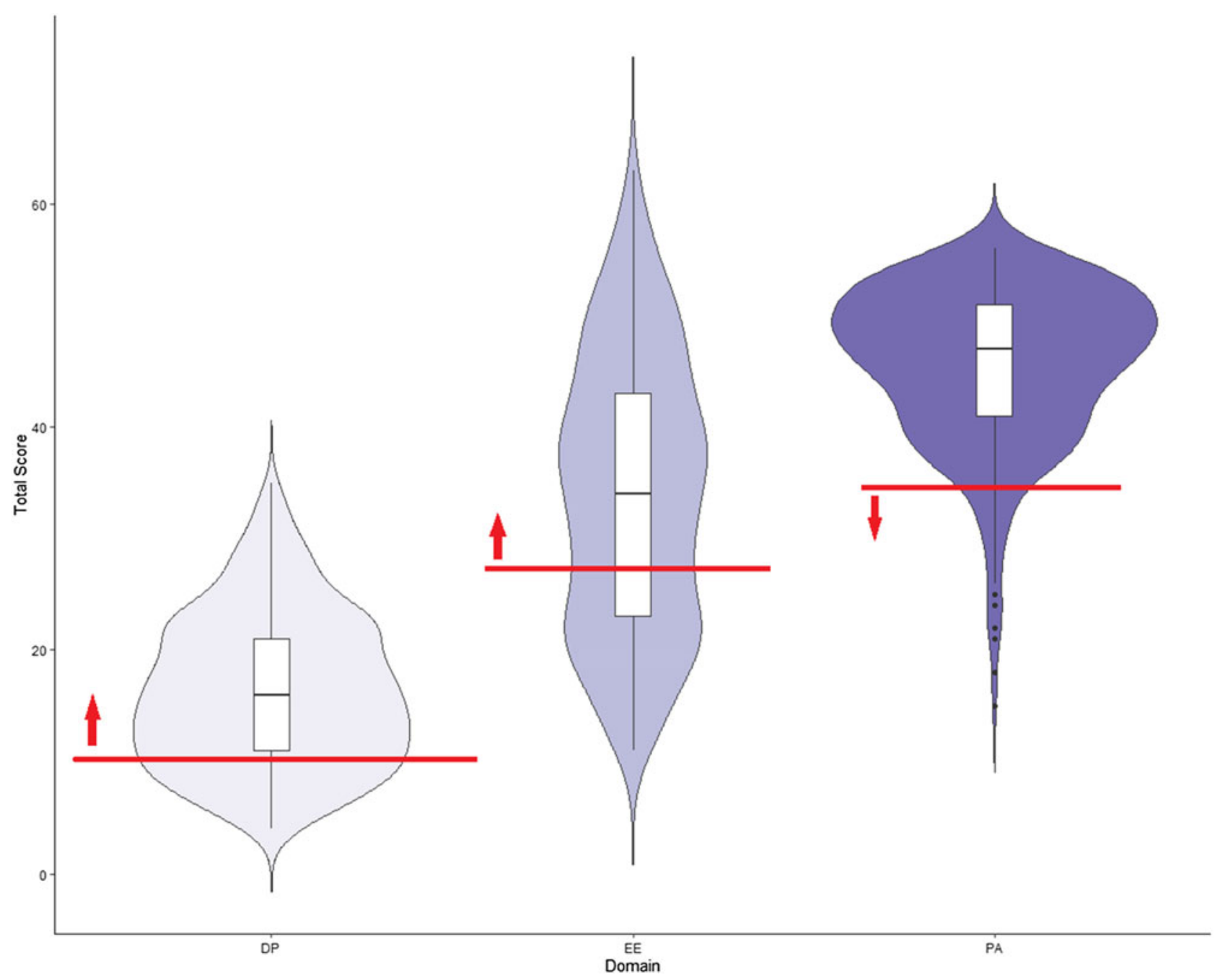

Figure 1. Violin plot showing threshold and distribution for burnout. Red lines indicate burnout threshold with respect to each domain. Arrows indicate all participants who met or exceeded the threshold for burnout. DP, depersonalization; EE, emotional exhaustion; PA, personal achievement. 


\section{RESULTS}

A total of 384 respondent surveys were included in the final analysis after exclusion of 43 surveys where only the demographic information was completed. Respondents were primarily male $(213 / 383,55.6 \%)$ and married $(327 / 384,85.2 \%)$ with a median [IQR] of 17.5 [7.2526.0] years of experience since residency.

Respondent MBI mean domain scores were emotional exhaustion 34.07 [23-43.25], depersonalization 16.35 [11-21.25], personal accomplishment 45.64 [41-51]. A total of $86.1 \%(329 / 382)$ met at least one of the criteria for burnout. Plots for mean domain score and thresholds can be seen in Figure 1.

The majority of respondents of the PHQ-9 (217/374; $58.0 \%$ ) scored as "minimal-none" for depression while those scoring as mild, moderate, moderately severe, and severe were $24.3 \%, 11.5 \%, 4.0 \%$, and $2.1 \%$, respectively. Of respondents, $14.3 \%$ (53/371) contemplated suicide during their EM career, and of those, 22/371 (5.9\%) had considered suicide in the past year.

The logistic regression model correctly classified $86.5 \%$ of cases and explained $33.0 \%$ of the variance in burnout. Physicians aged 30-39 (compared with those $40-49$ years) were almost four times more likely (95\% confidence interval [CI], 1.03-15.1) to suffer from burnout. Physicians who were CCFP-EM trained were 2.7 (95\% CI, 1.27-5.8) times more likely to suffer from burnout compared with FRCPC trained physicians. Finally, physicians with any indication of depression on the PHQ-9 were 43.7 times (95\% CI, 5.9-321.8) more likely to suffer from burnout compared with those who score in the lowest "minimal" category.

\section{DISCUSSION}

In this national survey of Canadian EM physicians in the immediate period before COVID-19, an alarming number met the criteria of burnout by the MBI-HSS. Beyond simply meeting the dichotomous outcome, respondents unfortunately far exceeded the predefined thresholds (Figure 1). Additionally, EM physicians screened for moderate/severe depression $3 \times$ higher than the general population. ${ }^{10}$ and had alarming rates of reported suicidal ideation. These results are consistent with the EM literature from the United States showing rates of burnout ranging from 65 to $80 \%,{ }^{3}$ and the Canadian Medical Association study showing 19\% of respondents contemplated suicide within their lifetime. ${ }^{1-4}$ (Additional references available in the online Supplemental Appendix.)

The strengths of this study involve the methods to increase the reach out to EM physicians using snowball techniques, social media, and posters at a national conference. Scales of measure were chosen with validity evidence, and rigorous statistical methods were used. Limitations for this study include the potential for selection bias. As a result of trying to reach a wide audience by means of a snowball methodology, we were unable to calculate a response rate, because the denominator is unknown. This cannot be considered population-based data due it being a convenience sample.

The long-term health effects for frontline workers due to COVID-19 should be a significant concern to government, hospitals, and doctors both during and after the pandemic. Current and future health systems and the patients they serve rely on healthy EM teams. Departments need to move toward making wellness interventions a priority now more than ever, and results of this survey can serve as a baseline for measurement to monitor and evaluate success of interventions and supports. The Canadian Medical Association has called for a national mental health support service, ${ }^{11}$ which would be a good first step, as comprehensive and centralized supports for EM physicians are needed. CAEP may be an important forum to provide support or advocate for services to this high-risk group.

\section{CONCLUSION}

In this survey of Canadian EM physicians just before the COVID-19 pandemic, the majority of physicians met the threshold for burnout and a concerning number of physicians have contemplated suicide. This baseline measurement will be useful as the COVID-19 pandemic will have serious and important healthcare implications during and after the pandemic.

Supplemental material: The supplemental material for this article can be found at https://doi.org/10.1017/cem.2020.431.

Financial support: The authors have no financial relationships relevant to this article to disclose.

Competing interests: The authors have no conflicts of interest relevant to this article to disclose.

Authors' Contributions: RL conceptualized and designed the study, drafted the initial manuscript, and reviewed and revised the 
manuscript. KVA designed the data collection instruments, collected data, carried out the initial analyses, helped draft and revised the manuscript. LR, SG, LF, and JF critically reviewed the manuscript for important intellectual content. All authors approved the final manuscript as submitted and agree to be accountable for all aspects of the work.

\section{REFERENCES}

Additional references available in the online Supplemental Appendix.

1. Canadian Medical Association. CMA Workforce Survey 2017; 2017. Available at: http://cma.andornot.com/en/surveydata/default.aspx (accessed January 18, 2020).

2. West CP, Dyrbye LN, Shanafelt TD. Physician burnout: contributors, consequences and solutions. $\mathcal{F}$ Intern Med 2018;283(6):516-29. doi: 10.1111/joim.12752.

3. Arora M, Asha S, Chinnappa J, Diwan A. Review article: burnout in emergency medicine physicians. Emerg Med Australas 2013;25(6):491-5.

4. Kane L, (2019 January 16) Medscape National Physician Burnout, Depression \& Suicide Report 2019. Available at: https://www.medscape.com/slideshow/2019-lifestyle-burnout-depression-6011056\#29.
5. Wallace JE, Lemaire JB, Ghali WA. (2009). Physician wellness: a missing quality indicator. Lancet 2009;374(9702): 1714-21.

6. Wu P, Styra R, Gold W. Mitigating the psychological effects of COVID-19 on health care workers. CMA7 2020;192(17): E459-E460. doi: 10.1503/cmaj.200519.

7. Lai J, Ma S, Wang Y, et al. Factors associated with mental health outcomes among health care workers exposed to coronavirus disease 2019. 7AMA Netw Open 2020;3(3): e203976. doi: 10.1001/jamanetworkopen.2020.3976.

8. Maslach C, Jackson SE, Leiter MP. Maslach Burnout Inventory Manual. 3rd ed. Palo Alto, CA: Consulting Psychologists Press; 1996.

9. Doulougeri K, Georganta K, Montgomery A. "Diagnosing" burnout among healthcare professionals: can we find consensus? Cogent Med 2016;3:1237605.

10. Kocalevent R-D, Hinz A, Brähler E. Standardization of the depression screener patient health questionnaire (PHQ-9) in the general population. Gen Hosp Psychiatry 2013;35(5): 551-5. doi: 10.1016/j.genhosppsych.2013.04.006.

11. Canadian Medical Association. Emergency Federal measures to care for and protect Canadians during the COVID-19 pandemic. Available at: https://www.cma.ca/sites/default/ files/pdf/Media-Releases/CMA-Brief-federal-emergencymeasures-pandemic.pdf (accessed June 6, 2020). 